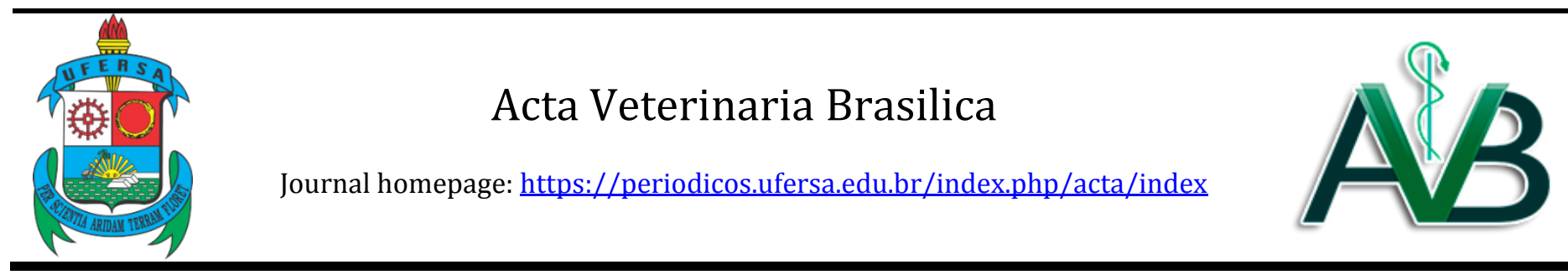

Original Article

\title{
Effects of leptin and adinopectin on cardiovascular, respiratory and haematological systems of healthy dogs
}

\author{
Genilson Fernandes de Queiroz ${ }^{*}$, Hildita Siméa de Andrade Chaves ${ }^{1}$, João Modesto-Júnior ${ }^{1}$, Valéria Veras de
} Paula $^{1}$, Julia Maria Matera ${ }^{2}$, André Menezes do Vale ${ }^{1}$ Luã Barbalho de Macêdo ${ }^{1}$

1 Departamento de Ciências Animal, Universidade Federal Rural do Semi-Árido, Mossoró- RN, Brasil.

2Departamento de Cirurgia, Faculdade de Medicina Veterinária e Zootecnia, Universidade de São Paulo, São Paulo-SP, Brasil.

A R T I C L E I N F O

\begin{tabular}{l} 
Article history \\
Received 08 March 2017 \\
Received in revised form 04 July 2017 \\
Accepted 19 July 2017 \\
\hline Keywords: \\
Adipocytokines \\
Adipose tissue \\
Cardiology \\
Hematology \\
Hormones
\end{tabular}

\begin{abstract}
A B S T R A C T
Adipocytokines are substances produced by adipocytes responsible for the regulation of several physiological processes. Among those substances, leptin and adiponectin have been intensively investigated because of their possible effects on metabolism, reproduction, hematopoiesis and cardiovascular system. The current study aimed to assess the effects of adipocytokines, leptin and adiponectin on cardiac and respiratory functions, as well as on the hematological parameters of healthy female dogs of different breeds. Parameters of rectal temperature, diastolic blood pressure, systolic blood pressure, mean arterial pressure, pulse, heart rate and respiratory rate were evaluated in fifty two healthy female dogs. Blood samples were collected for complete blood count and plasma leptin and adiponectin measurement via ELISA technique. There was no difference in circulating levels of adipocytokines among the different breeds $(p \leq 0,05)$. Negative correlation between leptin and mean corpuscular hemoglobin concentration was found, while it was positive regarding systolic blood pressure, heart rate and breathing. Adiponectin was positively correlated with red blood cells and platelets and negatively with heart rate, respiratory rate, diastolic blood pressure and pulse. Adipocytokines, leptin and adiponectin, exert regulatory effects on cardiorespiratory function and hematopoiesis in healthy female dogs.
\end{abstract}

\section{INTRODUCTION}

Leptin and adiponectin are cytokines produced by the adipose tissue whose participation is important in many physiological processes, such as energy homeostasis, metabolism, body temperature and blood pressure control, reproduction, inflammation, hematopoiesis and immune system (BLÜHER, 2012).

Leptin is a pleiotropic hormone produced mainly by white adipose tissue, with influence on blood pressure, immune activation, erythropoiesis and metabolic control (PARK; AHIMA, 2015). Researches conducted in humans have shown an association between high levels of leptin and hypertension (CATLI et al., 2014) which is independent of adiposity in both normotensive and hypertensive individuals (SAMARA et al., 2008).
According to Park; Ahima (2015) leptin is important in the modulation of innate and adaptive immune responses, acting on neutrophil chemotaxis and assisting in the phagocytosis macrophage process. It has been shown that absence of leptin causes immunosuppression in mice and humans, which is reversed after leptin administration (UNER; SULU, 2012). Among other leptin physiological actions, its effects on platelet aggregation, angiogenesis and vascular smooth muscle cell proliferation stand out (BLÜHER, 2012).

Adiponectin is secreted exclusively by the adipose tissue (YIANNIKOURIS et al., 2010) and plays an important role in the cardiovascular and endocrine system (SHIBATA et al., 2014) working as a biomarker for cardiovascular diseases due to its vascular protective effect (AHEARN et

*Corresponding author: genilson@ufersa.edu.br 
al., 2015). Reduction in plasma adiponectin is associated with a risk of developing cardiovascular diseases in humans, especially hypertension and atherosclerosis (AHEARN et al., 2015; SHIBATA et al., 2014).

Most of the research on leptin and adiponectin effects on the cardiovascular and respiratory system has been conducted on obese and/or diabetic rats and humans (LUBKOWSKA et al., 2015; SENADOR et al., 2009; SIKKA et al., 2010). Moreover, there are few reports of these effects on haematological parameters in domestics animals. Thus, this study aims to investigate the influence of leptin and adiponectin on cardiac and respiratory function as well in hematological parameters in healthy female dogs.

\section{MATERIALS AND METHODS}

The Animal Ethics Committee of the Federal Rural University of Semi Arid approved the experimental protocols (n. $\left.{ }^{\circ} 25 / 2013\right)$ and procedures adopted for the research.

The study evaluated fifty two (52) healthy female dogs of different breeds, between 1 and 7 years old, from a private kennel in the city of Mossoró.

The animals were clinically examined, measuring the parameters of rectal temperature, diastolic blood pressure, systolic blood pressure, mean arterial pressure, pulse, heart and respiratory rate. Blood samples were collected for complete a blood count (RBC count, hemoglobin dosage, hematocrit, mean corpuscular volume, mean corpuscular hemoglobin concentration, leukocytes, neutrophils, eosinophils, lymphocytes, monocytes and platelets) as well as measurement of plasma adiponectin and leptin.

Heart rate was checked by auscultation of the heartbeat with the aid of a phonendoscope. Respiratory rate was recorded according the number of thoracic movements. Rectal temperature was measured with a digital thermometer which was introduced into the animal's rectum.

Blood pressure and pulse were determined by applying the oscillometric method with a blood pressure measurement device for oscillometry (PetMAP ${ }^{\circledR}$ - Ramsey Medical, Inc, Florida-USA). The cuff for measuring pressure was placed in the distal radio-ulnar joint, around the median artery.

After clinical assessment, $5 \mathrm{~mL}$ of blood were collected from the jugular or cephalic vein, and stored in two tubes: one containing anticoagulant (EDTA) and another without it. The blood with anticoagulant was used to determine haematological parameters, using an automatic analyzer (SDH-3 VET ${ }^{\circledR}$ - Labtest Diagnostica SA). For obtaining plasma, the blood without anticoagulant was used, which was centrifuged for 10 minutes at $3200 \mathrm{rpm}$ and then stored in a refrigerator until the measurement of adipokines.

In order to measure leptin and adiponectin doses, the ELISA method was used with the following commercial kits: for leptin (Leptin Canine Elizabethan EZCL-31K, EMD-Millipore), and for adiponectin (mouse adiponectin EZMADP-60K, Millipore EMD-). Tests were performed following the manufacturer's recommendations. Absorbance was read with a microplate reader (Human Humareader Single ${ }^{\circledR}$ ) with the filter set at $450 \mathrm{~nm}$. The results were then plotted on graph paper, putting the absorbance on the ordinate axis and the standard concentration on the abscissa. Thus, the standard curve was drawn and the concentrations were determined by instrumental methods of analysis.

Data were expressed as mean \pm standard deviation and minimum and maximum values evaluated by the statistical program SigmaPlot (Systat Software, San Jose, CA) version 12.0. Before evaluating whether leptin and adiponectin were different in the breed of dogs, the Shapiro-Will test was performed to verify if these proteins had a normal distribution pattern. Statistical differences between breeds for each hormone were obtained using Kruskal-Wallis and Dunn tests. Associations between hormone levels within each parameter were obtained by Pearson correlation. $\mathrm{P}$ values $<0.05$ were considered significant.

\section{RESULTS}

The animals' average age was 3,41 \pm 1,19 years, with clinical and hematological parameters within limits considered normal for the species. There was no difference in leptin and adiponectin plasma concentrations in the different breeds as shown in Table 1.

Table 1. Effect of breeds on plasm leptin and adiponectin concentration in bitches.

\begin{tabular}{lll}
\hline \multicolumn{1}{c}{ Breeds (no of animals) } & Leptin $\left(\right.$ ng.mL $\left.\mathrm{m}^{-1}\right)$ & Adiponectin $\left(\mathrm{ng} \cdot \mathrm{mL}^{-1}\right)$ \\
\hline Bulldog (12) & $0,9136( \pm 0,44)^{\mathrm{a}}$ & $281,11( \pm 45,76)^{\mathrm{b}}$ \\
Maltês (11) & $1,2585( \pm 1,05)^{\mathrm{a}}$ & $277,78( \pm 48,37)^{\mathrm{b}}$ \\
Schnauzer (7) & $0,6914( \pm 0,41)^{\mathrm{a}}$ & $305,55( \pm 52,81)^{\mathrm{b}}$ \\
Shitzu (14) & $0,8629( \pm 0,41)^{\mathrm{a}}$ & $282,56( \pm 51,35)^{\mathrm{b}}$ \\
Yorkshire (8) & $1,0547( \pm 1,42)^{\mathrm{a}}$ & $279,58( \pm 36,50)^{\mathrm{b}}$ \\
\hline
\end{tabular}

Values are mean \pm SEM.

$\mathrm{a}, \mathrm{b}$ Within a column, means with different superscripts are significantly different $(p \leq 0,05)$. 
There was negative correlation with leptin and mean corpuscular hemoglobin concentration (MCHC), and positive regarding systolic blood pressure, and heart and respiratory rates according to Table 2.
A positive correlation was seen between adiponectin and red blood cells and platelets, and a negative one regarding diastolic blood pressure, pulse, heart and respiratory rates (Table 2 ).

Table 2. Plasm leptin and adiponectin levels correlate with clinical and hematological parameters.

\begin{tabular}{lll}
\hline Clinical Parameters & Leptin & Adiponectin \\
\hline Respiratory Rate & $0,276(0,04)^{*}$ & $-0,327(0,01)^{*}$ \\
Heart Rate & $0,341(0,01)^{*}$ & $-0,325(0,01)^{*}$ \\
Pulse & $0,130(0,35)$ & $-0,382(0,005)^{*}$ \\
Systolic Blood Pressure & $0,281(0,04)^{*}$ & $-0,175(0,21)$ \\
Diastolic Blood Pressure & $0,88(0,53)$ & $-0,306(0,02)^{*}$ \\
\hline Hematologial Parameters & & Adiponectin \\
Erythrocytes & Leptin & $0,333(0,01)^{*}$ \\
MCHC & & $0,09(0,49)$ \\
Platelets & $0,153(0,27)$ & $0,439(0,001)^{*}$ \\
\hline
\end{tabular}

Number in parenthesis represents probability, *significant difference at $p \leq 0,05$. MCHC: Mean Corpuscular Hemoglobin Concentration.

\section{DISCUSSION}

This paper reports the relationship of leptin and adiponectin in healthy female dogs' breeds and their influence on cardiac, respiratory and hematopoietic functions. It was found that breed exerts no effect on leptin concentration in female dogs with resemblance to what was observed by Ishioka et al. (2007). However, when the authors distributed the animals by weight categories, higher levels were observed in animals with higher body condition scores.

The body's total adipose tissue mass is the main factor associated with blood leptin concentrations. However, other factors can cause fluctuations in such concentrations as reductions caused by fasting, moderate exercise and cold, and increases caused by food after fasting, glucocorticoids and insulin (NEGRÃO; LICINIO, 2000). It was not possible to verify the relationship between leptin and body condition scoring, but the authors tried to eliminate other factors responsible for causing fluctuations in its concentrations such as healthy animals, in resting conditions and without any medication.

There are no reports regarding the effects of breed on adiponectin concentration in dogs. Under this study's conditions, it was found that the breed do not exert influence on circulating adiponectin levels. However, this result must be analyzed carefully, bearing in mind the reduced number of animals.

Effects of adipocytokines on the cardiovascular system have been investigated in mice and humans with results conflicting. Furthermore, most studies investigated leptin in rodents fed with a standard diet. Research carried out by Senador et al. (2009) reported that, in diabetic rats, high blood pressure caused by obesity can occur in the absence of leptin receptor signaling. On the other hand, Sikka et al. (2010) demonstrated that reductions in blood pressure in non-obese diabetic mice occur through leptin-dependent or independent mechanisms. Recently, Simonds et al. (2014) confirmed the effects of leptin on heart rate and blood pressure increase in rats, via leptin receptor-expressing in the region of the dorsomedial hypothalamus. Leptin seems to exert effects on the heart rate and systolic pressure in dogs, but it was not possible to determine the mechanisms by which these effects and obesity or the mechanism by which leptin exerts these effects on dogs.

Evidences show possible regulatory effect of adiponectin on blood pressure in humans. In a group of obese adolescents with or without diabetes mellitus type 2, Shatat et al. (2009) observed that low serum adiponectin levels are associated with increased 24 hour systolic and diastolic pressure. Iwashima et al. (2004) reported that hipoadiponectinemia is an independent risk factor for hypertension and is considered a factor for predicting future hypertension. Investigating the relationship of adiponectin in a group of normotensive human patients, Baden et al. (2013) showed negative correlation between adiponectin and blood pressure. Most studies are focused on individuals with hypertension or hipoadiponectemia with little information on the relationship between normotensive individuals and normal to high levels of adiponectin. This study demonstrates, for the first time, that adiponectin is negatively correlated with cardiovascular parameters (diastolic blood pressure, pulse and heart rate) in healthy female dogs. 
Studies in animal models have reported some evidence of stimulant effect of leptin on ventilation. Some studies have showed increased respiratory rate, minute ventilation and tidal volume in ob/ob mice, present even before the onset of obesity, when compared to wild type mice (GROEBEN et al., 2004; TANKERSLEY et al., 1998). Chronic leptin replacement restores the rapid breathing pattern and the diminished lung compliance associated with the obese phenotype (TANKERSLEY et al., 1998). The present study demonstrated correlation between leptin and respiratory rate in healthy female dogs. While clinical studies provide supporting evidence to the mouse-model observations indicating the critical role of leptin in ventilatory control, this is the first study to report the effect of leptin regarding respiratory function in healthy female dogs. Further studies are needed to clarify the pathophysiological mechanisms of leptin on respiratory function in dogs.

The effects of adiponectin on respiratory function have been studied in healthy adolescents (NEMET et al., 2003), asthmatic and non-asthmatic obese (CIESLAK et al., 2013) and healthy adults (MARTINEZ; FORTES; ANJOS, 2011) with varying results. Nemet et al. (2003) demonstrated a negative correlation between adiponectin and oxygen consumption. On the other hand, Martinez; Fortes; Anjos (2011) detected weak positive correlation between the variables in healthy adults and no correlation was observed between the variables in obese asthmatic and non asthmatic in the study of Cieslak et al. (2013) The results observed in the present research, suggesting a possible involvement in the respiratory activity. Further research investigating the relationship between adiponectin with spirometric variables and the presence of their receptors in breath control sites may explain the mechanisms and their relationship with respiratory function in dogs.

Adipocytes are one of the main components of the bone marrow microenvironment and produce a variety of proteins that act in hematopoiesis and metabolism (GIMBLE et al., 1996). Leptin, when in excessive quantities in the blood, induces proliferation and differentiation of hematopoietic cells and myelocytic precursors (SÁNCHEZ-MARGALET et al., 2003). In the current study, there was observed correlation just with mean corpuscular hemoglobin concentration. Reports on the effect of leptin on erythroid indicators diverge. A study evaluating the relationship between leptin and thyroid hormones in humans with chronic renal failure and transplanted patients showed no correlation of leptin with hemoglobin (MALYSZKO et al., 2006). Conversely, Lubkowska et al. (2015) observed negative relationship between leptin doses in the blood and red blood cells, hemoglobin and hematocrit. The negative relation between leptin and corpuscular hemoglobin concentration in this study suggests a possible effect of hypoxia on leptin concentration in female dogs. Studies in mice revealed that leptin tends to increase during prolonged hypoxia (CHAIBAN; BITAR; AZAR, 2008). The results of this study should be carefully analyzed, given the small number of animals, hematological parameters within the limits of normality, and animals of the same sex.

The role of adiponectin on hematopoietic cell proliferation differs among the researchers. A study suggests action of adiponectin on proliferation of hematopoietic stem cells by activating the receptor AdipoR1 in those cells (DIMASCIO et al., 2007). Moreover, studies of Matsubara et al. (2004) and Kohno et al. (2014) show a suppressive effect of adiponectin on bone marrow in vivo in humans. In this study, there was correlation between adiponectin and count of red blood cells and platelets suggesting a proliferative effect of adiponectin on hematopoiesis in healthy female dogs.

\section{CONCLUSION}

Dog breed has no effect on leptin and adiponectin concentrations. Leptin and adiponectin exert regulatory effects on cardiac function, respiratory and haematological parameters of healthy dogs.

\section{ACKNOWLEDGMENTS}

The authors thank Conselho Nacional de Desenvolvimento Científico e Tecnológico (CNPq, Brasília, Distrito Federal, Brazil) (CNPQ), Process $n^{\circ}$ 552327/2011-5 for financial support. H. S. A. Chaves was supported by Coordenação de Aperfeiçoamento de Pessoal de Nível Superior (CAPES, Brasília, Distrito Federal, Brazil).

\section{REFERENCES}

AHEARN, J. et al. Cardiovascular disease biomarkers across autoimmune diseases. Clinical Immunology, v. 161, n. 1, p. 59-63, 2015 .

BADEN, M. Y. et al. Association of adiponectin with blood pressure in healthy people. Clinical endocrinology, v. 78, n. 2, p. 226-231, 2013.

BLÜHER, M. Clinical relevance of adipokines. Diabetes \& metabolism journal, v. 36, n. 5, p. 317-327, 2012.

CATLI, G. et al. The relation of leptin and soluble leptin receptor levels with metabolic and clinical parameters in obese and healthy children. Peptides, v. 56, p. 72-76, 2014.

CHAIBAN, J. T.; BITAR, F. F.; AZAR, S. T. Effect of chronic hypoxia on leptin, insulin, adiponectin, and ghrelin. Metabolism, v. 57, n. 8, p. 1019-1022, 2008. .

CIESLAK, F. et al. Adiponectinemia e indicadores fisiológicos em adolescentes obesos asmáticos e não-asmáticos. Medicina (Ribeirao Preto. Online), v. 46, n. 4, p. 404-415, 2013.

DIMASCIO, L. et al. Identification of adiponectin as a novel hemopoietic stem cell growth factor. The Journal of Immunology, v. 178, n. 6, p. 3511-3520, 2007. 
GIMBLE, J. M. et al. The function of adipocytes in the bone marrow stroma: an update. Bone, v. 19, n. 5, p. 421-428, 1996.

GROEBEN, H. et a,l. The effect of leptin on the ventilatory response to hyperoxia. Experimental lung research, v. 30, n. 7, p. 559-570, 2003.

ISHIOKA, K. et al. Plasma leptin concentration in dogs: effects of body condition score, age, gender and breeds. Research in veterinary science, v. 82, n. 1, p. 11-15, 2007.

IWASHIMA, Y. et al. Hypoadiponectinemia is an independent risk factor for hypertension. Hypertension, v. 43, n. 6, p. 1318-1323, 2004.

KOHNO, K. et al. Management of erythropoiesis: cross-sectional study of the relationships between erythropoiesis and nutrition, physical features, and adiponectin in 3519 Japanese people. European journal of haematology, v. 92, n. 4, p. 298-307, 2014.

LUBKOWSKA, A. et al. Serum Adiponectin and Leptin Concentrations in Relation to Body Fat Distribution, Hematological Indices and Lipid Profile in Humans. International journal of environmental research and public health, v. 12, n. 9, p. 11528-11548, 2015.

MALYSZKO, J. et al. Adiponectin, leptin and thyroid hormones in patients with chronic renal failure and on renal replacement therapy: are they related?. Nephrology Dialysis Transplantation, v. 21, n. 1, p. $145-152,2006$.

MARTINEZ, E. C.; FORTES, M. S. R.; ANJOS, L. A. dos. Influence of nutritional status and VO2max on adiponectin levels in men older than 35 years. Arquivos brasileiros de cardiologia, v. 96, n. 6, p. 471-476, 2011.

MATSUBARA, M. et al. Relationships between plasma adiponectin and blood cells, hepatopancreatic enzymes in women. Thromb Haemost, v. 91, n. 2, p. 360-366, 2004.

NEGRÃO, A. B.; LICINIO, J. Leptina: o diálogo entre adipócitos e neurônios. Arquivos Brasileiros de Endocrinologia \& Metabologia, v. 44 , n. 3 , p. $205-214,2000$.

NEMET, D. et al. Adipocytokines, body composition, and fitness in children. Pediatric Research, v. 53, n. 1, p. 148-152, 2003.

PARK, H.; AHIMA, R. S. Physiology of leptin: energy homeostasis, neuroendocrine function and metabolism. Metabolism, v. 64, n. 1, p. 24-34, 2015.

SAMARA, A. et al. Leptin expression in Peripheral Blood Mononuclear Cells (PBMCs) is related with blood pressure variability. Clinica Chimica Acta, v. 395, n. 1, p. 47-50, 2008.

SÁNCHEZ-MARGALET, V. et al. Role of leptin as an immunomodulator of blood mononuclear cells: mechanisms of action. Clinical \& Experimental Immunology, v. 133, n. 1, p. 11-19, 2003.

SENADOR, D. et al. Cardiovascular and autonomic phenotype of $\mathrm{db} / \mathrm{db}$ diabetic mice. Experimental physiology, v. 94, n. 6, p. 648-658, 2009.

SHATAT, I. F. et al. Relationship between adiponectin and ambulatory blood pressure in obese adolescents. Pediatric research, v. 65, n. 6, p. 691-695, 2009

SHIBATA, Rei et al. The potential of adipokines as therapeutic agents for cardiovascular disease. Cytokine \& growth factor reviews, v. 25, n. 4, p. 483-487, 2014.

SIKKA, G. et al. Leptin is essential in maintaining normal vascular compliance independent of body weight. International Journal of Obesity, v. 34, n. 1, p. 203-206, 2010.

SIMONDS, S. E. et al. Leptin mediates the increase in blood pressure associated with obesity. Cell, v. 159, n. 6, p. 1404-1416, 2014
TANKERSLEY, C. G. et al. Leptin attenuates respiratory complications associated with the obese phenotype. Journal of Applied Physiology, v. 85 , n. 6 , p. 2261-2269, 1998.

UNER, A. G.; SULU, N. In vivo effects of leptin on lymphocyte subpopulations in mice. Immunobiology, v. 217, n. 9, p. 882-888, 2012.

YIANNIKOURIS, F. et al. Adipokines and blood pressure control. Current opinion in nephrology and hypertension, v. 19, n. 2, p. 195, 2010. 